\title{
Impact of a Sport Education Season on Students' Table Tennis Skills and Attitudes in China's High School
}

\author{
Xu Chenchen, Gao Rong, and Xu Shuaijing
}

\begin{abstract}
The purpose of this study is to investigate the impact of sport education model on students' skills and attitudes in table tennis course in high school. Sixty-four students (aged 16-17) from a senior high school in China participated in either a 16 lesson unit using the traditional sport model (TSM) $(n=28)$, or a 16 lesson season following the sport education model $(\mathrm{SEM})(n=36)$. The results indicate that both classes made significant improvements in their skills, while SEM students made more progress in forehand drive and serve than TSM students did. In addition, students in SE class also developed more positive learning attitudes and became more interested in table tennis class. Compared with TSM, SEM provides students with equal opportunities of game playing and skill practicing with their teammates for a long season. These opportunities allow students to built affinity with their teammates and experience the joy of game. The interest of learning is therefore inspired, causing better table tennis skills and learning attitude.
\end{abstract}

Index Terms-Table tennis, sport education model, skill, learning attitude.

\section{INTRODUCTION}

Sport education model (SEM) was originated from the game theory, where Daryl Siedentop (1982) believed that sport could be viewed as a subject matter of physical education. He therefore designed this pedagogical model to provide students authentic sport experiences in Physical Education [1].The aim of SEM is to cultivate students to be competent, literate, and enthusiastic sports players. Professor Siedentop believed that physical education should not only be limited to teach students techniques and tactics, but also to make students know about the unique sports culture and cultivate their habits of exercising [2]. As an innovative physical education model, SEM is widely praised and exerted in many sports classes, overturning the traditional sports model. Elizabeth Cohen demonstrated that sport education model can improve students' sports skills and tactics [3]. Oleg Sinelnikov believed that the SEM had positive effects on students' social development [4]. Tristan concluded that the SEM could build a positive impact on students' sports attitude [5]. Hastie believed that students could develop skills better

Manuscript received March 24, 2019; revised August 14, 2019. This work was supported in part by the Beijing Normal University Interdisciplinary Research Foundation for the First-Year Doctoral Candidates. Grant No.BNUXKJC1825.

$\mathrm{Xu}$ Chenchen and Gao Rong are with the school of physical education and sports, Beijing Normal University, Beijing, 100875, China (e-mail: 11122016043@bnu.edu.cn, gaorong@bnu.edu.cn).

Xu Shuaijing is with the Information Science Technology Department, Beijing Normal University, Beijing, 100875, China (e-mail: 201731210001@mail.bnu.edu.cn). and apply ability in the competition situation under SEM [6]. In recent years, Chinese experts and scholars began to do some research on this teaching model. For example, Gao Hang stressed that the SEM attaches importance to our sport culture and humanity [7]. This pedagogy has been tested successful all over the world, from Australia to English, American, Japan, Hong Kong and so on. However, SE model is not widely applied in PE classes of China.

This study explores whether SEM is a valid teaching pedagogy for the high school table tennis class in China. After experiments, we conclude that sport education model is suitable in senior high schools' table tennis class in China.

\section{Methodology}

\section{A. Participants and Setting}

1) School

We chose NO.2 Affinity High school of Beijing Normal University as our case-study school, a key senior high school situated in the capital of China. We limited the number of students as 36 per table tennis class to make sure each student can get enough participation in the class.

\section{2) Teacher}

The teacher is a table tennis coach graduated from Beijing Normal University (BNU) with more than 10 years' table tennis teaching experience. In order to control variables, both classes were taught by the same teacher.

\section{3) Students}

64 students (aged 16-17) from two eleventh-grade classes were chosen to participate in this study. They should attend one lesson per week for 16 weeks in a semester, and each lesson should last for 40 minutes. During this semester, teacher taught a table tennis unit to both class using different instructional approaches, SEM and TSM. The controlled class (28 students), set as traditional sports class (TS class), was taught using a traditional model. In this class, the main aim was the development of table tennis skills, and the class center was the teacher where students should follow instructions of the teacher. The experimental class (36 students), set as sport education class (SE class), was taught by the same teacher using sport education model.

\section{B. Season Content}

\section{1) Sport education unit}

In the season, SE class students participated in table tennis course which was designed and taught following the principles of sport education, namely, seasons, affiliation, formal competition, record keeping, festivity and 
culminating event.

Season: We set one semester as a long season. Students in SE class were involved to practice and play games in the pre-season, the season and finals.

Affiliation: In the pre-season (lesson 1-lesson2), the teacher introduced the SEM to students and divided them into 6 mixed-ability teams. In order to ensure fairness, we allocated students with different skill levels to 6 teams (6 students per team) in the same proportion. The skill level was determined according to their pre-tests' results of skills and game rating during pre-season. Besides, gender was also taken into consideration and each team included 2 boys at least. Each team had their own team name, logo and final goal, which increased the affinity of all team members. Team members' roles consisted of captain, coach, scorekeeper, referee, players and so on. Students experienced much fun from roles acting, and improved their social ability and manage ability from interactions. Skillful players try to help others rather than dominating the games. Every student therefore got the same opportunities to take a participation.
This approach made the 36 students have a sense of belonging to their own team be willing to fight for the team and have affinities with each other.

Formal competition \& Record keeping: On regular practicing days (lesson 3 - lesson 7) in the season, students first completed a warm-up under the guidance of their team's fitness leader. Then they practiced basic skills taught by the teacher with their teammates. After that, the competition format was adopted, in which students interspersed practicing table tennis skills with different modified games. The modified games were shown in Table I. They were designed not only to improve students' table tennis movements, but also to help them use those skills and tactics. During lesson 8 to lesson 14, the official games were introduced and each team took part in the games in each lesson. All the modified games and official games required teams to earn score points. Total team points were then calculated and recorded to team score chart. The team who got the highest final scores got the winner.

TABLE I: MODIFIED GAMES DESIGNED FOR SPORT EDUCATION CLASS

\begin{tabular}{|c|c|}
\hline "Modified Games & Specific Details \\
\hline $\mathbf{A}$ & $\begin{array}{l}\text { Members of a team run around a table and hit the ball with backhand drive in turn. Each one hits one time } \\
\text { then keep running and tries hard to keep the ball on the table. } 3 \text { minutes later, the teacher records the total } \\
\text { numbers of a team. }\end{array}$ \\
\hline B & $\begin{array}{l}\text { A member uses forehand drive to hit the ball with the team coach. Next member follows up to play if the ball } \\
\text { falls on the ground. } 3 \text { minutes later, the teacher records the total numbers of a team. }\end{array}$ \\
\hline $\mathbf{C}$ & $\begin{array}{l}\text { A member uses combined movements to hit the ball with the team coach. Next member follows up to play if } \\
\text { the ball falls on the ground. } 6 \text { minutes later, the teacher records the total numbers of a team. }\end{array}$ \\
\hline $\mathbf{D}$ & Team leader will transfer his points to team members to play 7 - point system formal games. \\
\hline
\end{tabular}

Festivity and Culminating event: In the end of the season (lesson 15), the final game was hold in the classroom, where the top 2 teams in the final rankings played for the title race and others as spectators watched the game. After that, all students cheered to celebrate the whole season's improvements and their performances.

In the lesson 16, they were tested post-skills and post-attitude.

\section{2) Traditional unit}

In the controlled class, TSM students participated in units of table tennis in a non-team-based and teacher-directed format. At the beginning of the unit (lesson 1 - lesson 2), students had pre-tests of their skills and attitudes towards table tennis class. During lessons 3 to lesson 14, instruction focused on the same skills taught in the sport education class, including forehand drive, backhand drive and topspin serve. Students' interviews were arranged in lesson 15 . In the 16 lesson, their post-tests of skills performance and attitudes were tested.

Table II shows details of 16 lessons of both pedagogies.

\section{DATA COLlECTION AND DATA ANALYSIS}

Data were drawn from pre-test and post-test of table tennis skills and attitudes of two classes (TS class \& SE class). Collection tools included questionnaire of students' attitude, tests of students' skill performance and the students' interview results. The analysis of collected data were conducted using the statistical software version 20.0. Descriptive statistics were analyzed using T-test. The level of significance was set at $p<0.05$.

\section{A. Pre-unit and Post-unit Attitudes of Both Classes}

All students finished a questionnaire to test their attitudes of table tennis learning in lesson 1 and 16, respectively. The attitude questionnaire contained 34 items anchored on three attitude components (cognitive, emotional, behavior disposition). The questionnaire had good liability and validity, which had been approved by 6 professors and had a Cronbach Alpha reliability coefficient of $0.88(r>0.6)$. The attitude questionnaire used a 5-point Likert-type scale ranging from 1 (strongly dislike) to 5 (strongly like).

The comparison of attitude differences (including the dimensions of cognitive, emotional and behavior disposition) between SE class and TS class was shown in Table III. The results of pre-test, post-test, D-value and P-value were shown in the third, fourth, fifth and sixth column, respectively.

\section{B. Skill Performances of Both Classes}


The assessments of students' skills were also completed in the first and last lesson of the study, respectively. Their performances of three skills including forehand drive, backhand drive and topspin serve were assessed. The comparisons of pre-test and post-test skill performance of SE class and TS class were shown in Table IV and Table V, respectively. The post-tests of skill performances of both classes were also compared and analyzed, shown in Table VI.

TABLE II: UNIT PLANS FOR THE TWO FORMATS



TABLE III: THE COMPARISON OF LEARNING ATTITUDES DIFFERENCE BETWEEN SPORT EDUCATION CLASS AND TRADITIONAL SPORTS CLASS

\begin{tabular}{|c|c|c|c|c|c|}
\hline Event & Model & $\begin{array}{l}\text { Mean(SD) } \\
\text { Pre }\end{array}$ & $\begin{array}{l}\text { Mean(SD) } \\
\text { Post }\end{array}$ & $\Delta$ & $\mathbf{P}$ \\
\hline \multirow[t]{2}{*}{ Attitude } & Sport Education & 125.55 & 140.09 & 14.54 & \multirow{2}{*}{$.000^{* * *}$} \\
\hline & Traditional & 128.54 & 128.36 & -0.18 & \\
\hline Cognitive & Traditional & 39.54 & 38.21 & -1.33 & .021 \\
\hline \multirow[t]{2}{*}{ Emotional } & Sport Education & 22.91 & 26.50 & 3.59 & \multirow[t]{2}{*}{.035} \\
\hline & Traditional & 22.43 & 23.89 & 1.46 & \\
\hline $\begin{array}{c}\text { Behavior } \\
\text { disposition }\end{array}$ & Traditional & 66.57 & 66.25 & -0.32 & $.000^{* * *}$ \\
\hline
\end{tabular}

TABLE IV: THE COMPARISON OF PRE-TEST AND POST-TEST OF SKILL PERFORMANCE IN SPORT EDUCATION CLASS

\begin{tabular}{|c|c|c|c|c|c|}
\hline Event & $\begin{array}{c}\text { Measuring } \\
\text { time }\end{array}$ & Mean. & Std. & $\mathbf{T}$ & $\mathbf{P}$ \\
\hline \multirow[b]{2}{*}{ Backhand drive } & pre & 17.20 & 11.442 & \multirow{2}{*}{-5.744} & \multirow{2}{*}{$.000^{* * *}$} \\
\hline & post & 31 & 10.614 & & \\
\hline \multirow{3}{*}{ Forehand drive } & pre & 12.31 & 8.174 & \multirow{2}{*}{-5.636} & \multirow{2}{*}{$.000^{* * *}$} \\
\hline & post & 23.17 & 8.665 & & \\
\hline & pre & 3.86 & 0.430 & -6.273 & $.000^{* * *}$ \\
\hline Topspin serve & post & 4.60 & 0.651 & & \\
\hline
\end{tabular}




\section{Student Interview}

All students from both SE class and TSM class were interviewed in lesson 15 . Interview contents were students' feelings about the course, collected in the last week of the study.

\begin{tabular}{|c|c|c|c|c|c|}
\hline Event & $\begin{array}{c}\text { Measuring } \\
\text { time }\end{array}$ & Mean. & Std. & $\mathbf{T}$ & $\mathbf{P}$ \\
\hline \multirow{3}{*}{ Backhand drive } & pre & 21.68 & 7.533 & -2.676 & .013 \\
\hline & post & 27.54 & 11.787 & & \\
\hline & pre & 11.14 & 5.475 & -4.396 & $.000^{* * *}$ \\
\hline \multirow[t]{2}{*}{ Forehand drive } & post & 18.00 & 9.002 & & \\
\hline & pre & 3.75 & 0.585 & 0.273 & .787 \\
\hline Topspin serve & post & 3.71 & 0.460 & & \\
\hline
\end{tabular}

TABLE VI: THE COMPARISON OF SKILl PERFORMANCE BETWEEN SPORT EDUCATION ClaSS AND TRADITIONAL SPORT CLASS

\begin{tabular}{|c|c|c|c|c|c|}
\hline Event & Model & Mean. & Std. & $\mathbf{T}$ & $\mathbf{P}$ \\
\hline Backhand drive & $\begin{array}{c}\text { Sport Education } \\
\text { Traditional }\end{array}$ & $\begin{array}{c}31 \\
27.5\end{array}$ & $\begin{array}{l}10.614 \\
11.787\end{array}$ & 1.226 & .225 \\
\hline Forehand drive & $\begin{array}{c}\text { Sport Education } \\
\text { Traditional }\end{array}$ & $\begin{array}{c}23.17 \\
18\end{array}$ & $\begin{array}{l}8.665 \\
9.002\end{array}$ & 2.314 & .05 \\
\hline Topspin serve & $\begin{array}{c}\text { Sport Education } \\
\text { Traditional }\end{array}$ & $\begin{array}{c}4.6 \\
3.71\end{array}$ & $\begin{array}{l}0.651 \\
0.460\end{array}$ & 6.083 & $.000^{* *}$ \\
\hline
\end{tabular}

\section{RESULTS}

\section{A. Students' Attitudes}

According to D-value and P-value from the fifth and sixth lines of Table III, we find that the learning attitudes of students in SE class including cognitive, emotional and behavior disposition improves significantly after the season, where $P_{a}=0.000, P c=0.021, P_{e}=0.035, P_{b}=0.000(<0.05)$. On the other hand, the value of students' attitudes in TS class shows a slightly negative growth.

\section{B. Students' Skills}

In order to gain conclusion effectively, we compared the pre-test and post-test results of skill performance of SE class and TS class in Table IV and Table V. From the third line and sixth line in each table, we find students in both classes made significant progress in forehand and backhand drive, while only students in SE class improve their performance of topspin serve.

The post-test results of both classes were also compared in Table VI to further prove the conclusion that we have drawn from Table IV and Table V. Table VI illustrates that there is no significant difference between the two classes in backhand drive and forehand drive after one semester of table tennis lessons, $P=0.225$ and $P=0.05$ ( $\geqslant 0.05$ ). Whereas, the performance of two classes in topspin serve is significantly different, where $P=0.000(<0.05)$. It is consistent with the conclusion that only students in SE class make improvements in topspin serve.

\section{Students' Interviews}

The interview materials supports students' perceptions of the skill improvements, attitudes toward lessons, their perception of the teacher, and the preference of the instructional approach. The TS class students reported that they improved their skill levels, but most of them shown negative attitude to table tennis lessons in traditional sports model. One student from the traditional class commented as following:

"My skills improve a little, which is good. But I don't like to pick up the ball all the time because it makes me feel bored and tired."

The answer of the students from TS class were analyzed and summarized into 7 aspects:

1) Most of them thought that the traditional sports class did not arouse their interest in learning and practicing.

2) Most of them believed that it took a long time to learn skills without obvious improvements of skills.

3) Some of them felt bad because each had to practice skills with one classmate from the beginning of the semester to the end.

4) They expected more harmonious and closer relationship with the teacher.

5) Most of them felt tired because there was no chance to have a rest during a lesson.

6) They wanted to experience the SEM next semester.

7) Some of them wanted to learn more table tennis skills.

Students in SE class were convinced that they had learned more, especially about the teamwork and tactics than before. One student explained:

"This way is more effective. Fortunately, SE model make me know the table tennis culture, the cooperation, the skills, techniques and how to win the game."

The thoughts of the students from SE class were analyzed and summarized into 5 aspects:

1) Most of them thought that they could make many friends in class and have more chances to communicate with each other.

2) Most of them found that the atmosphere of their class was relaxing, making them reduce their study pressures.

3) All of them considered that they had made great progress 
in the competition and gained lots of experience from practice. They were more interested in table tennis than before.

4) Most of the students mentioned that their techniques were improved.

5) They realized that the importance of the teamwork and cooperation, as well as their sense of responsibility.

As a conclusion, from the interview summaries of both classes, the SEM students shown more positive attitudes towards the table tennis class.

\section{DISCUSSION}

We draw a conclusion from Table III that the learning attitudes of students in SE class improves significantly after the season, while there is a slightly negative growth in TS class. From the interview, we find that students prefer sport education class. The reason may be that SEM can bring students with opportunities to make friends and experience the fun from games, as analyzed in report [8]. Pill found that intimacy between team members was the key to enhance the motivation of learning [9]. We believe that role-play in a team is another important factor. Team members' roles such as captain, coach, scorekeeper, referee and players give team members a chance to establish the sense of responsibility. The goal of getting higher scores for the team promote the sense of trust and team cooperation between team members. In SE class, most advanced students were willing to help lower-level teammates and some of them even did further research of table tennis on their own. Lower-level students tried their best to improve themselves because of the sense of group honor, the responsibilities of their roles and the thank of their teammates. Students experienced the fun of games, sports and friendship from roles acting. The relaxing and friendly learning atmosphere also cause the positive learning attitudes of table tennis. On the contrary, students in TS class had to passively accept knowledge and skills from the teacher. No wonder their attitudes towards table tennis class are not positive.

The results shown in Table IV, Table $\mathrm{V}$ and Table VI illustrate that students in both classes improve their forehand and backhand drive skills effectively. Although students in SE class practiced more and benefited from the games, students in TS class had more opportunities to practice with the teacher, and were more familiar with the teacher's feeding styles. We also believe that the difficulties of forehand and backhand drive and the nervousness influenced the results more or less. It is difficult for beginners to have a good command of the two difficult skills and hit the ball at right place all the time. We suppose the differences in forehand and backhand drive would be obvious between the two class with more lessons, and we will continue the experiments to verify the conjecture. Table IV, Table V and Table VI also show that only students in SE class make significant improvements in topspin serve. We believe the improvements benefit from games, the unique content of SEM through the season. Each game needed to serve and receive the ball to ensure the game started and finished, so students in SE class got more chance to practice topspin serve.

\section{CONCLUSION}

After the data collection, analyzing and discussion, we come to the following conclusions:

1) Both of the teaching pedagogy, sport education model and traditional sports model, can affect students' learning attitude and sports ability.

2) Sport education model makes students more interested in table tennis, while traditional sports model makes students feel bored and lack of motivation.

3) Both sport education model and traditional sports model have a positive impact on students' table tennis skills. However, the level of improvements students in SE class is better than that of TS model.

4) Sport education model is suitable in senior high schools' table tennis class in China.

\section{CONFLICT OF INTEREST}

All authors declared no conflict of interest.

\section{AUTHOR CONTRIBUTION}

$\mathrm{Xu}$ Chenchen was responsible for the overall experimental design and writing of the article, and Gao Rong was responsible for the article structure and research ideas of the article. Xu Shuaijing was responsible for data processing and translation proofreading. Lastly, all authors had approved the final version.

\section{ACKNOWLEDGMENT}

$\mathrm{Xu}$ Chenchen shows great thanks to prof. Mingyan Yao and Ms. Mengxue Kang for their great help of this research.

\section{REFERENCES}

[1] D. Siedentop, P. A. Hastie, and H. Mars, "Complete guide to sport education," Human Kinetics, 2011.

[2] D. Siedentop, "Movement and sport education: current reflections and future images," presented at Commonwealth and International Conference on Sport, Physical Education, Recreation and Dance, Brisbane, Australia. 1982.

[3] E. G. Cohen, R. A. Lotan, Designing Group Work: Strategies for the Heterogeneous Classroom, Teachers College Press, 2014.

[4] P. A. Hastie and O. A. Sinelnikov, "Russian students' participation in and perceptions of a season of sport education," European Physical Education Review, 2006, vol. 12, no. 2, pp. 131-150.

[5] T. L. Wallhead and N. Ntoumanis, "Effects of a sport education intervention on students' motivational responses in physical education," Journal of Teaching in Physical Education, 2004, vol. 23, no. 1 , pp. 4-18.

[6] P. A. Hastie, "Skill and tactical development during a sport education season," Research Quarterly for Exercise and Sport, 1998, vol. 69, no. 4, pp. 368-379.

[7] H. Gao et al., "Analysis of sport education and the enlightenment on the development of competitive sports in China," Sports Science and Technology Literature Bulletin, 2006, vol. 14, no. 5, pp. 9-10.

[8] P. Hastie, "Applied benefits of the sport education model," Journal of Physical Education, Recreation \& Dance, 1998, vol. 69, no. 4, pp. 24-26.

[9] S. Pill, "A teacher's perceptions of the sport education model as an alternative for upper primary school physical education," ACHPER Australia Healthy Lifestyles Journal, 2008, vol. 55, no. 2-3, p. 23.

Copyright (C) 2019 by the authors. This is an open access article distributed under the Creative Commons Attribution License which permits unrestricted use, distribution, and reproduction in any medium, provided the original work is properly cited (CC BY 4.0). 


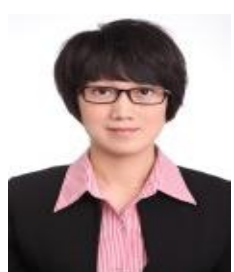

$\mathrm{Xu}$ Chenchen is pursuing the $\mathrm{PhD}$ degree in School of Physical Education and Sports in Beijing Normal University. Her main research field is sport education in high school, and motor rehabilitation for disabled children in China.

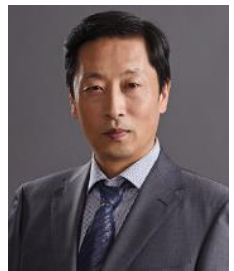

Gao Rong worked in the public physical education teaching and research office of Northwest Normal University. Now he is working in the Sports Department of Beijing Normal University. He has published more than 30 papers in academic journals such as Sports Science, Journal of Beijing Sports University and Sports Journal.

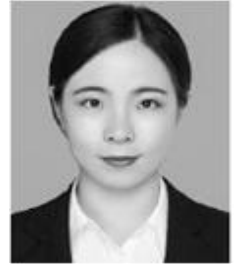

Xu Shuaijing received the B.S. degree from Beijing Normal University, Beijing, China, in 2015, where she is currently pursuing the Ph.D. degree with the College of Information Science and Technology. Her major is computer application technology. Her major interests are big data, computer vision, and deep learning. 